\title{
EFFECT OF GENERATING CAPACITOR BANK SWITCHING TRANSIENT OVER VOLTAGES AND MITIGATING OF TRANSIENT OVERVOLTAGES
}

\author{
Dr.T.Murali Mohan \\ Department of EEE \\ Jntuk University of College, Kakinada, \\ Andhra Pradesh, India
}

\author{
T.Ramya Durga \\ Department of EEE \\ Jntuk University of College, Kakinada, \\ Andhra Pradesh, India
}

\begin{abstract}
In the paper, it presents the increase of power factor and reduces the problems of power quality such as the effect of generating capacitor bank switching transient overvoltages on the power system network side. Among this problem, the effects of generating transients and controlling the transients using the various mitigating techniques are used to control the transients in a specific distribution feeder line and also calculate the mathematical computations of quantities such as peak transient overvoltages, high-frequency inrush currents occur in each case. Mitigating values in each case is compared to other cases using MATLAB/Simulink Software.
\end{abstract}

Keywords-Capacitor bank switching, Energization, inrush current, Matlab/Simulink software, pre-insertion resistor, Current limiting reactor, Surge arresters, Transient Overvoltages.

\section{INTRODUCTION}

The generation of transients is inevitable in the power system network both in the generation side as well as the distribution side. These transients are produced during the switching operations of the circuit breakers. By switching operations of capacitors, high-frequency transients are produced with large magnitudes in small intervals of time. Normally these capacitor banks are shunt connected in a 3phase system. The opening and closing timings of capacitor banks decide the magnitude of the peaks both in current and voltage.

A distribution system is considered where the capacitor banks are required to the power factor was improved of the loads. That, in turn, improves the voltage and current of the system. The inherent presence of system inductance and incoming capacitance contribute to the high-frequency transient in switching operations. These transients are mitigated by using some controlling techniques such as pre-insertion resistor, preinsertion inductor, and pre-insertion impedance methods.
A distribution system is considered for study simulated separately for VCB switch was open and closed cases. Along with above some mitigation techniques are also simulated and studied.

\section{BASIC CONCEPT OF ENERGIZING CAPACITOR BANK SWITCHING TRANSIENTS}

Fig.1 shows a single line circuit of the generating capacitor bank switching transient. This circuit will be connected to the distribution side feeder line and used in the utility consumer side. The network provides a visionary introduction about the Energization CBS transients. Rs and Ls represent the resistance and inductance of source with a frequency of $60 \mathrm{~Hz}$ and also shunt capacitors are used. In this circuit, the load is connected after the VCB switch.

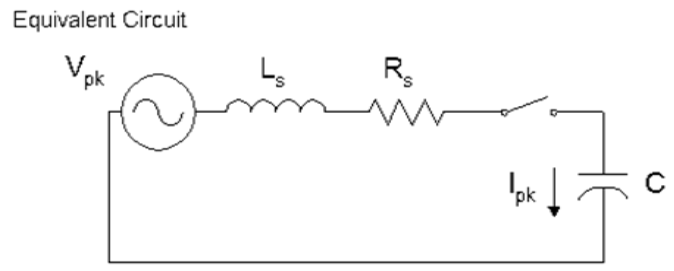

Fig .1.Single line diagram of capacitor bank switching transient Where:

$\mathrm{f}=$ frequency in $\mathrm{Hz}$.

$\mathrm{L}=$ source inductance, $\mathrm{H}$

$\mathrm{C}=$ capacitance of the capacitor bank, $\mathrm{F}$.

$\mathrm{Vpk}=$ peak voltage.

Ipk = peak inrush current.

$\mathrm{Z} 0=$ Surge impedance.

$\mathrm{f}=\frac{1}{2 \pi \sqrt{L C}}$

$I_{\text {peak }}=\frac{V \text { peak }}{Z o}$ 


\section{International Journal of Engineering Applied Sciences and Technology, 2019 \\ Vol. 4, Issue 7, ISSN No. 2455-2143, Pages 113-118 \\ Published Online November 2019 in IJEAST (http://www.ijeast.com)}

$\mathrm{Z}_{0}=\sqrt{\frac{L}{C}}$

\section{SYSTEM SYSTEM CIRCUIT REPRESENTATION}

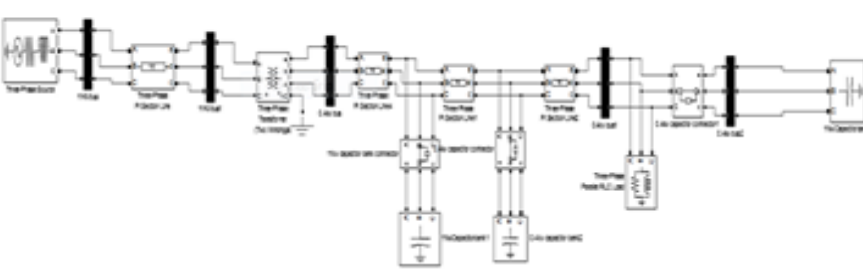

Fig 2: simulation of the Energization of capacitor bank switching.

These values are used to simulate the circuit using

MATLAB/Simulink software and the values used in the model are resistance, reactance, and capacitance. These values are important which are used in the three-phase shunt Capacitor bank, connected in shunt with the feeder line with a frequency of $60 \mathrm{~Hz}$. The capacitor bank produces a high magnitude of transient overvoltages and inrush currents.

Table -1 circuit data

\begin{tabular}{|c|c|}
\hline Parameters & Values \\
\hline Source & $110 \mathrm{kV}$ \\
\hline Distribution transformer & $110 / 22 \mathrm{kV}$ \\
\hline Load & P=10MW; Q=6.197 MVAr \\
\hline Power factor & 0.85 p.f \\
\hline Capacitor banks & 900 KVAr; 1400 KVAr \\
& 2.9 MVAr \\
\hline
\end{tabular}

In order to study the effect of the energization of capacitor banks a three-phase circuit is considered shown in fig 3 . Switch closing and opening of the capacitor bank is made to observe the transients generation. The given circuit diagram is simulated in MATLAB simulation software. A scenario of energization produces transients of larger magnitudes than the de-energization.

\section{EXPERIMENT AND RESULT OF GENERATING CAPACITOR BANK SWITCHING TRANSIENT OVER VOLTAGES}

In order to study the effect of the energization of capacitor banks a three-phase circuit is considered shown in fig 3 . Switch closing and opening of the capacitor bank is made to observe the transients generation. The given circuit diagram is simulated in MATLAB simulation software. A scenario of energization produces transients of larger magnitudes than the de-energization.

\section{A. Capacitor bank Energization}

The base case circuit diagram is shown in Fig.2 When the capacitor bank starts, energizing voltage is pulled to zero or voltage is overshoot or rebound complete and the switch will get closed. At that time the high magnitude peak transient overvoltages (2.5P.u) and high-frequency peak inrush current (2.7 KA) will produce but at phase A high transients and high inrush currents occurs and closing of switch happens at $6.5 \mathrm{~ms}$.

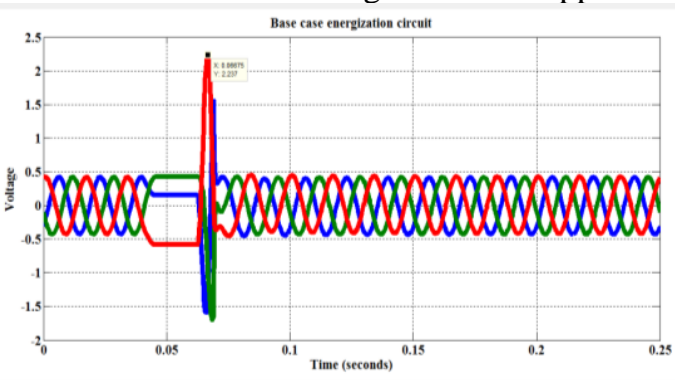

Fig. 3(a). transient overvoltages during energization

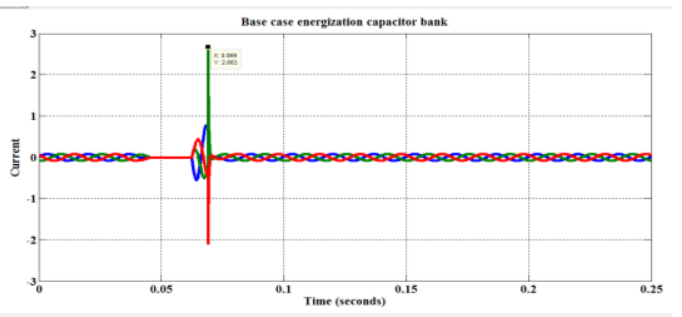

Fig. 3(b).Inrush currents during energization

Table -2 Transients are observed Energization of Capacitor bank at phase A Voltage and Current

\begin{tabular}{|c|l|}
\hline Phase A & $\begin{array}{l}\text { Maximum Peak observed } \\
\text { near the capacitor bank } \\
\text { when the switch at } \mathrm{t}=\text { peak }\end{array}$ \\
\hline voltages & 2.48 P.U \\
\hline current & $2567 \mathrm{~A}$ \\
\hline
\end{tabular}

\section{B. Capacitor bank De-Energization}

In the second case of the circuit, the shunt capacitor bank is opened in the feeder line. A capacitor bank is de-energized at time $0.05 \mathrm{~s}$. So produced transient overvoltages and inrush currents of phase A peaks are observed as 1.9246 P.U and 802.8 A respectively.

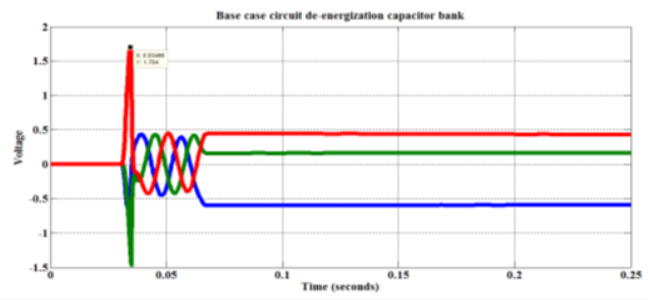

Fig. 4(a). Transient overvoltages produced during De- Energization of shunt Capacitor banks 


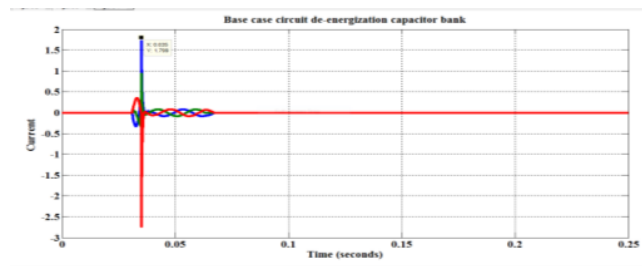

Fig .4(b).Inrush currents during de-energization

Table -3 Transients are observed De-Energization of Capacitor bank at phase A Voltage and Current

\begin{tabular}{|c|c|}
\hline Phase A & $\begin{array}{c}\text { Maximum Peak observed } \\
\text { near the capacitor bank when } \\
\text { the switch at } \mathrm{t}=\text { peak }\end{array}$ \\
\hline Voltages & $\mathbf{1 . 9 2 4 6 \text { P.U }}$ \\
\hline current & $\mathbf{8 0 2 . 8 \mathrm { A }}$ \\
\hline
\end{tabular}

Fig. 4(a) shows the transient overvoltages during deenergization of shunt Capacitor banks. Its value is observed as 1.9246 PU and also the inrush current 802.8 $\mathrm{A}$ is observed from fig 4(b).

\section{EXPERIMENT AND RESULT OF CONTROLLING CAPACITOR BANK SWITCHING TRANSIENTS}

\section{A. Controlling technique by pre-insertion resistor}

Case -1: Capacitor bank Energization

This is an old classic method that effectively reduces the high magnitude of the transient's overvoltages and high frequency of inrush currents. During capacitor bank energization a preinsertion resistor is connected in series with the capacitor bank. In the case of the three-phase system, three resistors are connected in series to three phases of a capacitor bank. In this case, an additional switch is used to disconnect the resistor in one-quarter of a cycle after the energization of the bank.

An additional switch is closed at $0.25 \mathrm{~s}$, as a result, the resistor was disconnected from the circuit which reduces the steadystate losses.

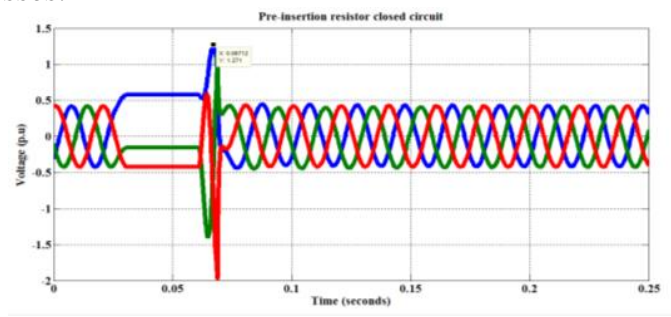

Fig .5 (a). the voltage at the controlled Energization capacitor bank using the Pre-insertion resistor

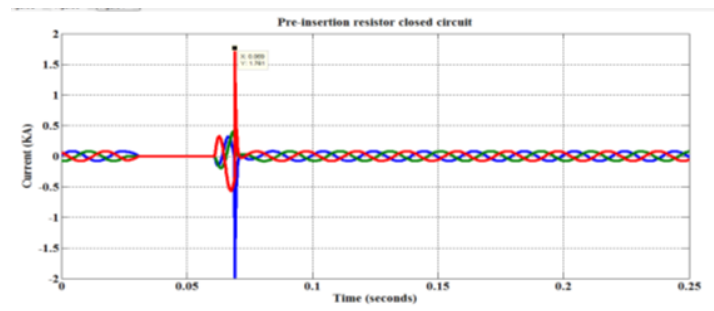

Fig.5 (b).current at the controlled Energization capacitor bank using the Pre-insertion resistor

Table -4 Transients are observed Energization of Capacitor bank at the Phase A Voltage and Current in pre-insertion resistor switched into the capacitor bank

\begin{tabular}{|c|c|}
\hline Phase A & $\begin{array}{c}\text { Maximum Peak observed } \\
\text { near the capacitor bank } \\
\text { when the switch at } \mathrm{t}=\text { peak }\end{array}$ \\
\hline Voltage & 1.48 P.U \\
\hline current & 1775.23 \\
\hline
\end{tabular}

In figure 5(a) transient overvoltage peak of phase $\mathrm{A}$ was observed $1.48 \mathrm{KV}$ and in fig 5(b) the inrush current peak of phase A, 1775.63 A was observed.

\section{B. Controlling technique by pre-insertion resistor}

Case 2: Capacitor bank De- Energization

This is an old classic method that effectively reduces the high magnitude of the transient's overvoltages and high frequency of inrush currents. During capacitor bank energization a preinsertion resistor is connected in series with the capacitor bank. In the case of the three-phase system, three resistors are connected in series to three phases of a capacitor bank. In this case, an additional switch is used to disconnect the resistor in one-quarter of a cycle after the energization of the bank. An additional switch is closed at $0.25 \mathrm{~s}$, as a result, the resistor was disconnected from the circuit which reduces the steady-state losses.

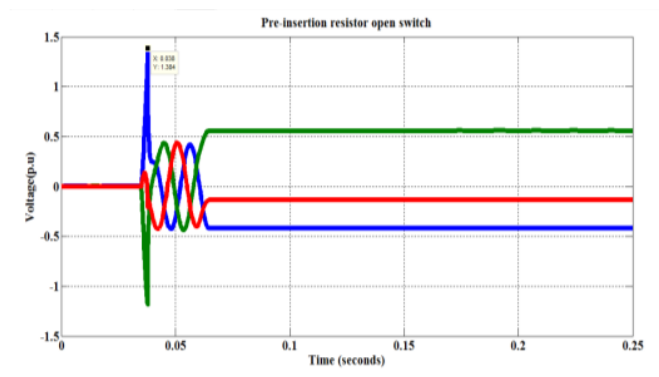

Fig. 6(a).voltage at the controlled De- Energization capacitor bank using the Pre-insertion resistor 
International Journal of Engineering Applied Sciences and Technology, 2019

Vol. 4, Issue 7, ISSN No. 2455-2143, Pages 113-118

Published Online November 2019 in IJEAST (http://www.ijeast.com)

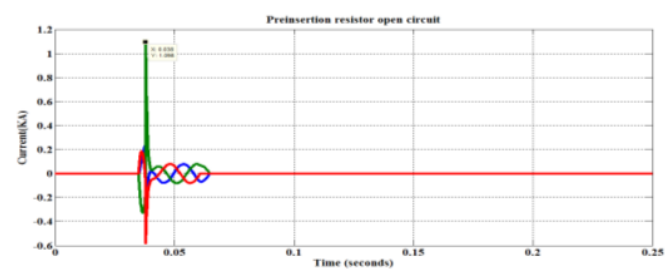

Fig.6 (b).current at the controlled DE-Energization capacitor bank using the Pre-insertion resistor

Table -4 Transient Magnitudes Observed the Energization of capacitor bank using at the Phase A voltage \& current in pre-insertion resistor are switched into the Capacitor bank.

\begin{tabular}{|c|c|}
\hline Phase A & $\begin{array}{c}\text { The maximum peak observed near } \\
\text { the capacitor bank when switched } \\
\text { at } \mathrm{t}=\text { peak }\end{array}$ \\
\hline Voltage (phase A) & $1.0 \mathrm{pu}$ \\
\hline Current (phase A) & $1.414 \mathrm{kA}$ \\
\hline
\end{tabular}

In figure 6(a) transient overvoltage peak of phase $\mathrm{A}$ was observed $1.0 \mathrm{KV}$ and in fig 6 (b) the inrush current peak of phase A, 1.414 KA was observed.

\section{Controlling technique by current limiting reactors}

Case 3: Capacitor bank Energization

The current limiting reactor is connected in series with a capacitor bank. This reactor can effectively reduce the peak value of inrush current (1.5 KA) but can't change instantly and also reduce transient overvoltages.

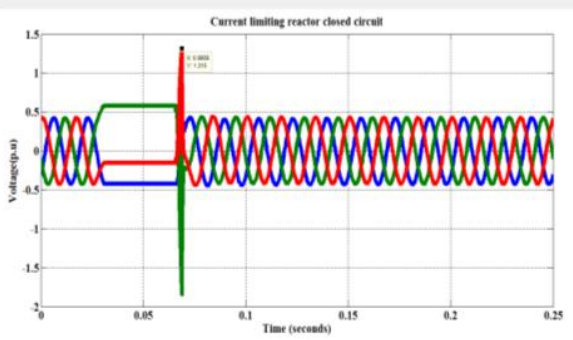

Fig.7 (a). Voltages at the when capacitor bank energizing it along with the current limiting.

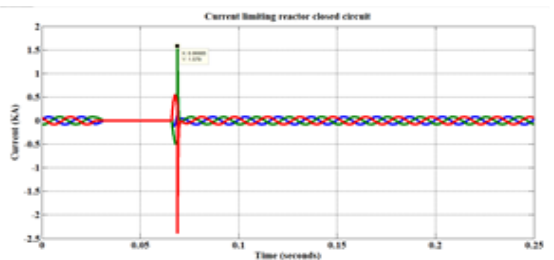

Fig.7 (b). Inrush current at the when capacitor bank energizing it along with the current limiting.

Table -5 Transient Observed Energization of capacitor bank at the phase A voltage and current in current limiting reactor switched long the capacitor bank

\begin{tabular}{|c|c|}
\hline Phase A & $\begin{array}{c}\text { The maximum peak observed } \\
\text { near the Capacitor bank when } \\
\text { the switch at } \mathrm{t}=\text { peak }\end{array}$ \\
\hline Voltage & 1.45 P.U \\
\hline Current & 1.5 KA \\
\hline
\end{tabular}

Fig.7 (a) and Fig. 7(b) show the Current limiting reactor of controlling the high magnitude transient overvoltages (1.45 P.u). The pre-insertion resistor reduces the transient overvoltages more than a current limiting reactor and highfrequency inrush currents $(1.5 \mathrm{KA})$ will get reduced by the current limiting reactor more compared to the pre-insertion resistor.

\section{Controlling technique by current limiting reactors}

Case 4: Capacitor bank De- Energization

The current limiting reactor is connected in series with a capacitor bank. This reactor can effectively reduce the peak value of inrush current (1.0 KA) but can't change instantly and also reduce transient overvoltages.

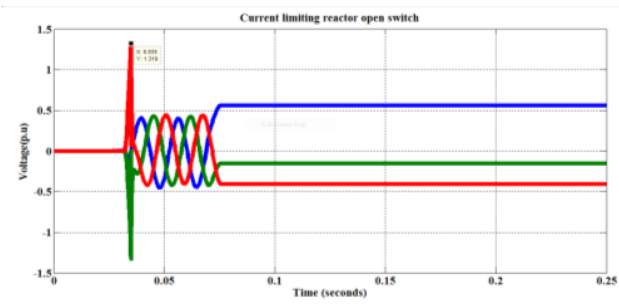

Fig. 8(a).Voltages at the when capacitor bank de-energizing it along with the current limiting.

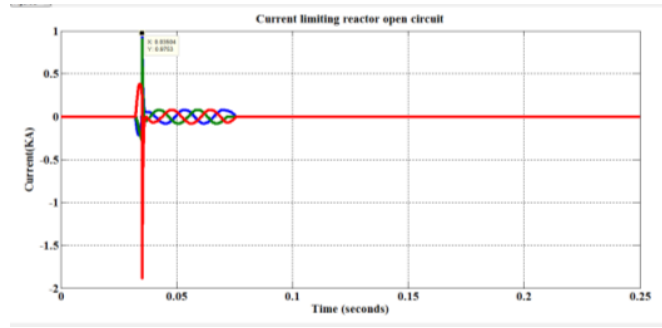

Fig. 8(b). Inrush current at the when the capacitor bank de-energizing it along with the current limiting.

Table -6 Transient Magnitudes Observed when capacitor bank DEEnergizing at the Phase A voltage\&current in the current limiting reactor.

\begin{tabular}{|c|c|}
\hline Phase A & $\begin{array}{c}\text { The maximum peak observed } \\
\text { near the capacitor bank when } \\
\text { switched at } \mathrm{t}=\text { peak }\end{array}$ \\
\hline Voltage (phase A) & $1.39 \mathrm{p.u}$ \\
\hline Current (phase A) & $1.0 \mathrm{kA}$ \\
\hline
\end{tabular}




\section{International Journal of Engineering Applied Sciences and Technology, 2019 \\ Vol. 4, Issue 7, ISSN No. 2455-2143, Pages 113-118 \\ Published Online November 2019 in IJEAST (http://www.ijeast.com)}

Fig.8 (a) and Fig. 8(b) show the Current limiting reactor of controlling the high magnitude transient overvoltages (1.39P.u). The pre-insertion resistor reduces the transient overvoltages more than a current limiting reactor and highfrequency inrush currents $(1.0 \mathrm{KA})$ will get reduced by the current limiting reactor more compared to the pre-insertion resistor.

\section{E. Controlling technique by the surge arrester}

Case 5: Capacitor bank Energization

Surge arresters are considered in controlling the transient overvoltages and inrush currents providing primary protection. The MOV gapless type arresters do not discharge the capacitor bank switching and these are connected across the capacitor bank phase to phase and phase to neutral.

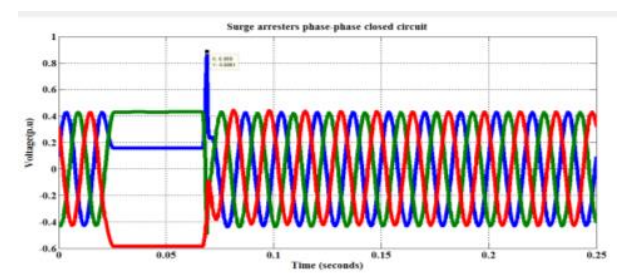

Fig. 9(a). Voltages at the controlled Energization of capacitor bank

\begin{tabular}{|c|c|}
\hline Phase A & $\begin{array}{c}\text { The maximum peak observed near } \\
\text { the capacitor bank when switched } \\
\text { att=peak }\end{array}$ \\
\hline Voltage (phase A) & 0.6 p.u \\
\hline Current (phase A) & $1.1 \mathrm{~A}$ \\
\hline
\end{tabular}

used in the surge arrester.

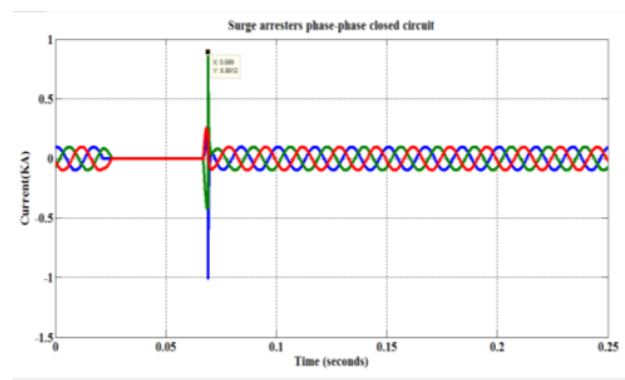

Fig .9(b).Current at the controlled Energization of capacitor bank used in the surge arrester.

Table -7 Transient Observed Energization of capacitor bank at the phase A voltage and current in surge arresters connected Phase-Phase in the capacitor bank

The surge, arresters reduces the high magnitude of transient overvoltages shown in fig .9(a) with transient overvoltage value (0.8 P.U) and in fig.9 (b) high frequency of inrush currents $(1.1 \mathrm{KA})$ connected in phase to phase.

\section{F. Controlling technique by the surge arrester}

Case 6: Capacitor bank Energization

Surge arresters are considered in controlling the transient overvoltages and inrush currents providing primary protection. The MOV gapless type arresters do not discharge the capacitor bank switching and these are connected across the capacitor bank phase to phase and phase to neutral.

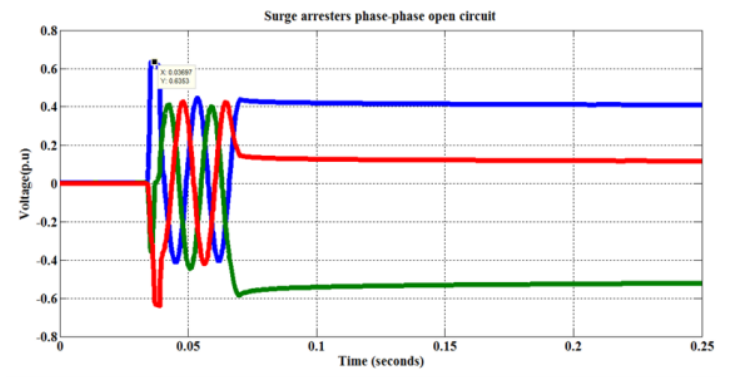

Fig .10(a). Voltages at the controlled DE- Energization of capacitor bank using the surge arresters

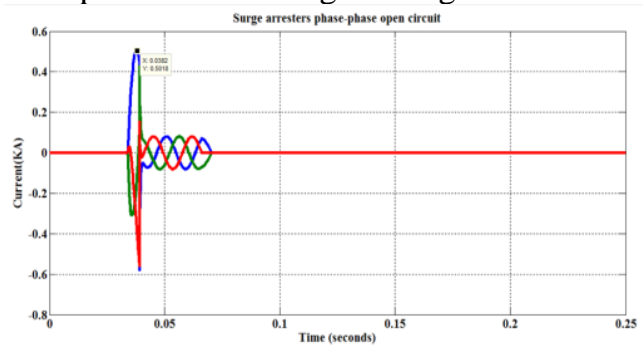

Fig .10(b). Current at the controlled DE- Energization of capacitor bank using the surge arrester.

Table -8 Transient Observed DE-Energization of capacitor bank at the phase A voltage and current in surge arresters connected PhaseNeutral in the capacitor bank

\begin{tabular}{|c|c|}
\hline Phase A & $\begin{array}{c}\text { The maximum peak observed } \\
\text { near the Capacitor bank when } \\
\text { the switch at } \mathrm{t}=\text { peak }\end{array}$ \\
\hline Voltage & 0.8 P.U \\
\hline Current & $1.1 \mathrm{KA}$ \\
\hline
\end{tabular}

\section{CONCLUSION}

In this paper, the main purpose is to identify the effects and causes of transient overvoltages and methods for solving the transients and the energization of CBS is the most important to initiate the transients. The generation of peak transient overvoltages and inrush currents are produced in this case, the switch will get closed at the peak value of TOV 2.5p.u and inrush current $2.7 \mathrm{KA}$. In order to reduce these peak values, some controlling techniques are used, which are a pre- 


\section{International Journal of Engineering Applied Sciences and Technology, 2019 \\ Vol. 4, Issue 7, ISSN No. 2455-2143, Pages 113-118 \\ Published Online November 2019 in IJEAST (http://www.ijeast.com)}

insertion resistor, Current limiting reactor, and surge arresters. In this pre-insertion resistor controls the high magnitude overvoltages and high-frequency currents. But if transients produce in second's, the pre-insertion resistor doesn't respond instantly and damage of equipment happens, this can be overcome by Current limiting reactors which effectively reduces the inrush currents but the cost is high, but it takes few seconds. The surge arresters provide the protection of the primary side and it responds in a fraction of seconds and it is most efficient and the cost is very low. So surge arresters are used in controlling the generation of transient overvoltages.

\section{ACKNOWLEDGMENT}

I would like to take this opportunity to express my Special thanks gratitude to my Project supervisor, Dr.T.Murali Mohan, Associate Professor, Electrical and Electronics Engineering, who has persistently and determinedly guided me during the whole course of this paper "(Effect of generating capacitor bank switching transient overvoltages and mitigating of transient overvoltages)". Secondly, I would also like to thank my parents (Tirupati Vidya sagar\&Usha Prasanna).

\section{REFERENCE}

[1] Greenwood, Electrical Transients in Power Systems, New York: John Wiley and Sons, pp. 37-46

[2] Ramasamy Natarajan, "Power System Capacitors" 2005 by Taylor\& Francis Group, LLC, International Standard Book Number-I 0:1-57444-710-6

[3] L. Van Der Slues, Transients in Power Systems John Wiley \&Sons, 2001. ISBNs: 0-471-48639-6;

[4] Grebe, T.E., "Application of Distribution System Capacitor Banks and Their Impact on Power Quality". IEEE Transactions on Industry Applications, 1996.32(3): P. 714-719.

[5] Sahib Abode wadded Ali, " Capacitor Banks Switching Transient In Power System" Cs Canada ISSN 1923-8460,2011

[6] Das. J. C. "Analysis And Control Of Large Shunt Capacitor Bank Switching Transient" IEEE Transactions On Industry Application, 2005. 41(6): P.1444-1451

[7] Dr. Mrs. Hina Chindwin, Chetan Upadhyay, Akil Vahora, Goutam Som, "Mitigation of switching overvoltage by Application of Surge arrester on capacitor bank",]JEET, Volume4, Issue 2, March - April (2013), pp. $37-45$

[8] M. F. Irizarry - Silvestrini PREPA T. E. VelezSepulveda, PREPA"Mitigation Of Back To Back Capacitor Switching Transient On Distribution Circuit"

[9] Lutz Gephardt Bernhard Richter, "Surge arrester application of -capacitor banks to mitigate Problems of switching restrikes"CIRED Vienna, 21-24 May 2007, Paper 0639
[10] Mehdi Zafar, Gevork B Gharehpetian And Taher Niknam "ANovel Parameter Estimation Method For Metal Oxide Surge Arrester Models", Dec 2011

[11]El-Hawary, M.E., "Introduction to Electrical Power Systems", L. Hanzo, Editor 2008, John Wiley \& Sons Inc: New Jersey.

[12] William D. Stevenson, J., "Elements of Power System Analysis". 4 ed, ed. F.J. Cerra. 1982: McGraw-Hill Book Company. 431.

[13] Nahvi, M. and J.A. Edminister, "Theory and Problems of Electric Circuits". 2003, McGraw Hill: New York.

[14]GREBE, T.E., "Customer Power Factor Correction, Capacitor Application Guide". 2005. p. 124.

[15] Program, W.S.U.C.E.E. and N.E.E. Alliance. (2003) "Energy Efficiency factSheet". Energy Ideas Clearing House, 4.

[16] Willis, H.L., "Power Distribution Planning Reference Book". 2004, Marcel Dekker Inc.

[17] Burke, J.J., "Power Distribution Engineering Applications and Fundamentals". Electrical Engineering and Electronics, ed. M.O. Thurston and W. Middendorf.1994, New York: Marcel Dekker, Inc. 356.

[18]Concepts. E., "Industrial Power Factor Analysis Guidebook" 1995: Portland. p.137.

[19]Grebe, T.E., "Application of Distribution System Capacitor Banks and their Impact on Power Quality". IEEE Transactions on Industry Applications, 1996.32(3): p. 714-719.

[20]Greenwood, A., "Electrical Transients In Power Systems". 1991, John Wiley \&Sons.

[21]McGranaghan, M.F., et al., "Impact of Utility Switched Capacitors on Customer

[22] Systems-Magnification at Low Voltage Capacitors". IEEE Transactions on Power Delivery, 1991: p. 908 - 914

[23]Witte, J.F., F.P. DeCesaro, and S. R. Mendis, "Damaging Long-Term Overvoltages on Industrial Capacitor Banks due to Transformer Energization Inrush Currents". IEEE Transactions on Industry Applications, 1994. 30(4): p.1107-1115. 